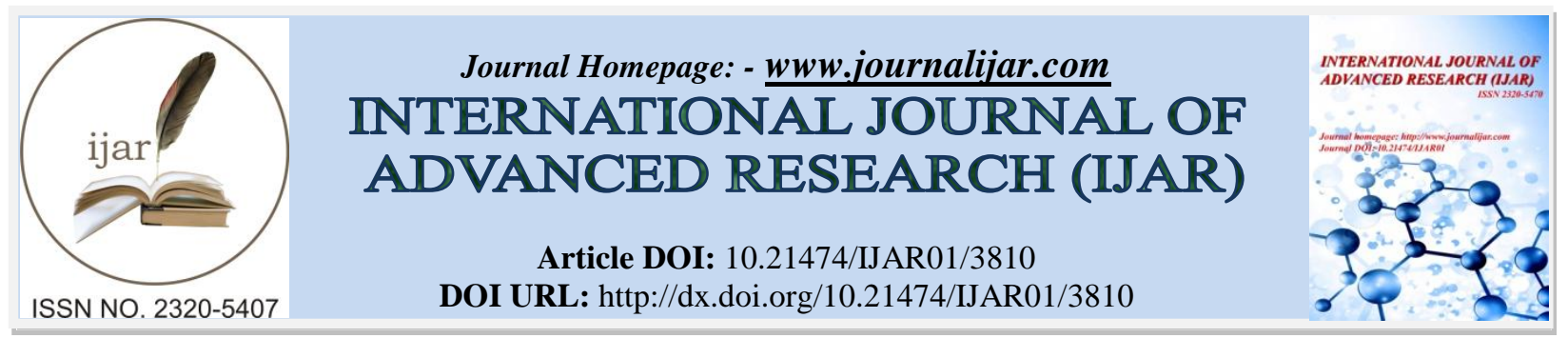

RESEARCH ARTICLE

\title{
FACETIOUS GREEN SYNTHESIS OF SILVER NANO PARTICLES USING LEAF EXTRACTS OF ALANGIUM SALVIFOLIUM [LAM.]
}

\author{
${ }^{*}$ Mita R. Patel ${ }^{1}$, Dr. Rasmikant A. Patel ${ }^{2}$, N. A. Pithawala ${ }^{3}$ and Dr. Kespi A. Pithawala ${ }^{3}$. \\ 1. Department of Chemistry, Gujarat Arts and Science College, Ahmedabad, Gujarat, India, 380006. \\ 2. Department of Chemistry, Municipal Arts and Urban Science College, Mehsana, Gujarat, India. \\ 3. Department of Biology, Gujarat Arts and Science College, Ahmedabad, Gujarat, India, 380006.
}

\section{Manuscript Info}

\section{Manuscript History}

Received: 03 February 2017

Published: April 2017

\section{Key words:-}

Silver nanoparticles,

Alangiumsalvifolium, Antibacterial

Activity, FTIR, DLS, SEM, TEM, EDX,
Final Accepted: 05 March 2017

\begin{abstract}
The current research in nanotechnology is chiefly aimed at easy, environment friendly and cost effective methods of green synthesis of nanoparticles. Here aqueous leaf extracts of Alangium salvifolium [Lam.] which act as reducing as well as capping agents were used for the formation of silver nanoparticles (SNP) from $0.1 \mathrm{mM} \mathrm{AgNO}_{3}$ solution. The SNP were formed within two hours and the formation was stable for weeks. The formation, characteristics, size and conformation of silver nanoparticles formed were carried out using UV-VIS spectroscopy, FTIR, Dynamic light scattering (DLS), SEM, TEM and EDX. Also the SNP formed this way showed fair antimicrobial activity against gram positive and gram negative bacteria. On the basis of result obtained it can be said that the easy production of silver nanoparticle using green chemistry can be effectively utilized in various fields in biomedical-nanotechnology as well as reducing the harmful microbial flora.
\end{abstract}

Copy Right, IJAR, 2017,. All rights reserved.

\section{Introduction:-}

Metals and metal salts nano particles can be formed using various synthetic, physical and green synthesis techniques [Sivakumar et al., 2012, , Awwad et al., 2013, Jain et al., 2009, Kora and Arunachala 2012, Roy et al., 2015, Patel et al., 2017 and Nabikhan et al., 2010]. Of all these approaches the most simple, easy and eco-friendly technique is through green route and today it is the most well-known strategy for nanoparticle amalgamation.[Joseph and Mathew 2014, Mehmood et al. , 2013, Rajeshkumar et al., 2013]. The metals and the salts most popularly used are the coinage metals as $\mathrm{Au}, \mathrm{Ag}$ and $\mathrm{Cu}$ however Fe, Zn,Pdand Pt have also been similarly used [Umer et al., 2012, Bonet et al., 1999, Najagi et al., 2011, Vilchis-Nestor et al., 2008, Zheng and Wang 2013, Shankar et al., 2004]. SNP are extensively put to use in therapeutics and biomedical research and hence needed to be fused by green course utilizing characteristic plant materials which is naturally saviour-faire as well as expands incorporation of conditions that are not harsh or leading to loss of vitality and instead does not have to utilize high molecular weight, and harmful chemicals which render it eco-friendly and biocompatible [Patil et al., 2012, Esumi et al., 1990, Anilkumar et al., 2007, Bali et al., 2006]. Bio-enthused formation of nanoparticles gives headway over harsh and physical strategies as it is quick and particular in their objective towards the applications where they can be used for their antimicrobial action [Sivaranjani and Meenakshi Sundaram 2013]. Medicinal plants are chiefly exploited as a part of extensive extents these days in view of the long term change against disorders after ordinary treatment [Patilet al., 2012]. In this investigation silver nano particles have been formed utilizing the green course i.e. from the

Corresponding Author:- Mita R. Patel.

Address:- Department of Chemistry, Gujarat Arts and Science College, Ahmedabad, Gujarat, India, 
aqueous leaf extracts of Alangium salvifolium regularly called 'Ankol' tree. This tree is of rare distribution in south Gujarat and the fruits of it are consumed by the locals and wood is exquisitely used as timber. The seeds have oils that is put to various medicinal usages as treatment of leprosy and skin disorders [Ratra and Gupta 2015, Xavier et al., 2005]

\section{Materials and Method:-}

Healthy leaves of Alangium salvifolium were hand plucked from the tree. Silver nitrate was bought from Hi-Media and all chemicals were of logical review with 98-100\% immaculateness measure as analytical reagents and chemical grade. Deionized and double distilled glass water was utilized throughout the experiment.

\section{Preparation of Leaf Extracts:-}

Fresh leaves of Alangium salvifolium were washed with deionized water and after that with refined water to free them of any dirt material. These were then subjected to dry in shaded space for around 7 days and then pounded into fine powder utilizing a clean sanitized kitchen grinder (mechanized, stainless steel cutting edges). This powder was stored in airtight glass bottles and was utilized for planning fluid concentrates. This was set up by including $1 \mathrm{~g}$ of leaf powder to $50 \mathrm{ml}$ of double distilled water and left overnight in refrigerator. The concentrate was filtered through Whatmann's filter paper No. 1 and the extract was utilized for formation of nanoparticles.

\section{Synthesis of Ag nanoparticles:-}

To $30 \mathrm{ml}$ of $0.1 \mathrm{mM} \mathrm{AgNO} 310 \mathrm{ml}$ of leaf extract was added and at interval of every 15 minutes colorimetric readings were taken at $410 \mathrm{~nm}$ to find the presence of formation of nano particles the colour change was an indication of formation of nano particles. These started forming within 15 minutes and continued up to 2 hours after that these particles were stable for about one month.

\section{Characterization techniques:-}

The biosynthesized silver nanoparticles were characterized by the following methods:

\section{Visual Observation:-}

A change of colour from pale yellow to reddish brown was observed in the solution after visible irradiation.

\section{UV Spectrophotometric analysis:-}

The characterization technique involved ultra-violet and visible spectroscopy. UV-Vis absorption spectra were measured using Systronic UV-117 spectrometer from 300nm to 700nm continuously and the leaf powder extract was used as the reference for the baseline correction.

\section{Fourier Transform Infrared Spectroscopy Analysis:-}

FTIR analysis was carried out to determine the functional groups present in leaf extract and their possible involvement in the formation of silver nanoparticles. FTIR analysis were carried using a FTIR SHIMADZU 8300 instrument where the samples were incorporated with $\mathrm{KBr}$ pellets to acquire the spectra. The results were compared for shift in functional peaks. A FTIR graph can be useful for preliminary investigation of surface chemistry of biogenic nanoparticles (i.e. those chemicals that contain carbon). This technique is widely used for identification of chemical residues such as amine, carbonyl and hydroxyl functional groups in a molecule [Angela et.al. 2016]. The FTIR analysis was performed with reduced silver nanoparticles. The synthesized AgNPs sample was mixed with $\mathrm{KBr}$ to make a pellet in the ratio of 1:100. The FTIR instrument with diffuse reflectance mode attachment. All measurements were carried out in the range of 400-4,000 cm-1 at a resolution of $4 \mathrm{~cm}-1$. For this fresh sample were sent for FTIR Analysis at Gujarat Laboratory, Ahmedabad. Samples with total of volume 1-2 ml were given in aqueous form formed by producing SNPs using the reduction reaction of $9 \mathrm{ml}$ of $0.1 \mathrm{mM}$ Silver Nitrate solution through $3 \mathrm{ml}$ of plant extract.

\section{Dynamic Light Scattering:-}

These studies were carried out to get to know the particle size distribution in the solution. The particle size comes out to be $60 \mathrm{~nm}$ and hence this can be further verified from EM analysis. 


\section{SEM \& EDX Analysis:-}

The surface morphology of silver nanoparticles was examined using a scanning electron microscopy (6010 LA, Jeol).The elemental composition of the synthesized silver nanoparticles was analyzed using Energy Dispersive XRay Spectrometer.

\section{TEM Analysis:-}

Since the particle sizes were small TEM studies were carried out to get to know the exact shape of the particles this was done using transmission electron microscope (JEM1400 Plus, Jeol). The particle sizes of about 30nm to 60nm can be seen clearly.

\section{Determination of antimicrobial activity:- Microorganisms:-}

The bacterial pathogens namely Staphylococcus aureus, Streptococcus pneumonia, Escherchia coli, Salmonella typhi, obtained from the Department of Microbiology, Gujarat Arts and Science College, Ahmedabad. These human pathogens were used to study the antibacterial activity. The nutrient broth, nutrient agar were used growing the test bacterial strains and were maintained on corresponding agar slants at $4^{\circ} \mathrm{C}$.

\section{Preparation of inoculums:-}

The bacterial pathogens were inoculated into sterile nutrient broth and incubated at $37^{\circ} \mathrm{C}$ for 24 hours until the culture attained a turbidity of $0.5 \mathrm{McFarland}$ units. The final inoculum was standardized to $105 \mathrm{CFU} / \mathrm{ml} \mathrm{by}$ diluting fresh cultures with sterile distilled water.

Colonies were suspended in $5 \mathrm{ml}$ of sterile $0.85 \%$ saline. The resulting suspension was vortex and the turbidity was adjusted to yield $2 \times 10^{6}$ cells/ml ( $\cong 0.5$ McFarland standards).

\section{Antibacterial activity:-}

Antibacterial activity of AgNPs was determined by the agar disc diffusion method [Balouiri et al., 2016]. Plates of Nutrient agar were evenly streaked across the complete surface throughout the petri plate so as to get a loan growth of the inoculums with the help of spread plate technique with a known volume of $0.01 \mathrm{ml}$ of active young culture with approx. Microbial count as $105 \mathrm{CFU} / \mathrm{ml}$. Sterile filter paper discs ( $5 \mathrm{~mm}$ diameter) were immersed in the $50 \mu \mathrm{l}$ of synthesized AgNPs $(10,20,30,40,50 \mu \mathrm{g} / \mathrm{ml})$ and allowed to dry at room temperature and it was placed over the Nutrient agar plates. Streptomycin $10 \mathrm{mcg} / \mathrm{disc}$ was used as positive control and the disc immersed in distilled water was used as negative control. The plates were incubated overnight at $37^{\circ} \mathrm{C}$ and the zone of inhibition around each disc was measured. Experiments were done in triplicate and mean values of zone diameter were taken.

\section{Results And Discussion:-}

An easy, cheap and a practical approach for eco-friendly synthesis of silver nanoparticles using aqueous leaf extract of Alangium salvifolium as both reducing and stabilizing agent, under the prescribed condition of room temperature has been used without the use of harsh inducers or hazardous chemical additives and/or severe chemical reactions. The formation of SNP was predicted visually from a color change and confirmed using UV-visible spectroscopy $(410 \mathrm{~nm})$,Figure-1, further authenticated by SEM,Figure-2, and also EDX, Figure-3, of SNP. Also using FT-IR Spectroscopy the characteristics of AgNP was confirmed, Figure-4,FTIR studies show peaks at 1634.4, 2933.7 and 3295.4 wave numbers confirming the formation of nano particles of silver. Size was determined c.a. as $60 \mathrm{~nm}$ using DLS,Figure-5, this was further affirmed from the TEM studies also the shape of the particles was known using transmission electron microscopy, Figure-6.

The prepared silver nanoparticles exhibited reasonable antibacterial activity,Graph-1 and 2. The effects were more pronounced on Gram-negative bacteria Salmonella typhii (MTCC: 733) and Escherichia coli (MTCC:425). The nanoparticles also showed prominent activity on Gram-positive bacteria Staphylococcus aureus (MTCC:96) and Bacillus cerus (MTCC:430). A bactericidal mode of action was observed more for both Gram-positive and Gramnegative bacteria by the nanoparticles as compared to plant extracts. 




Figure 1:- UV-VIS scan of SNP

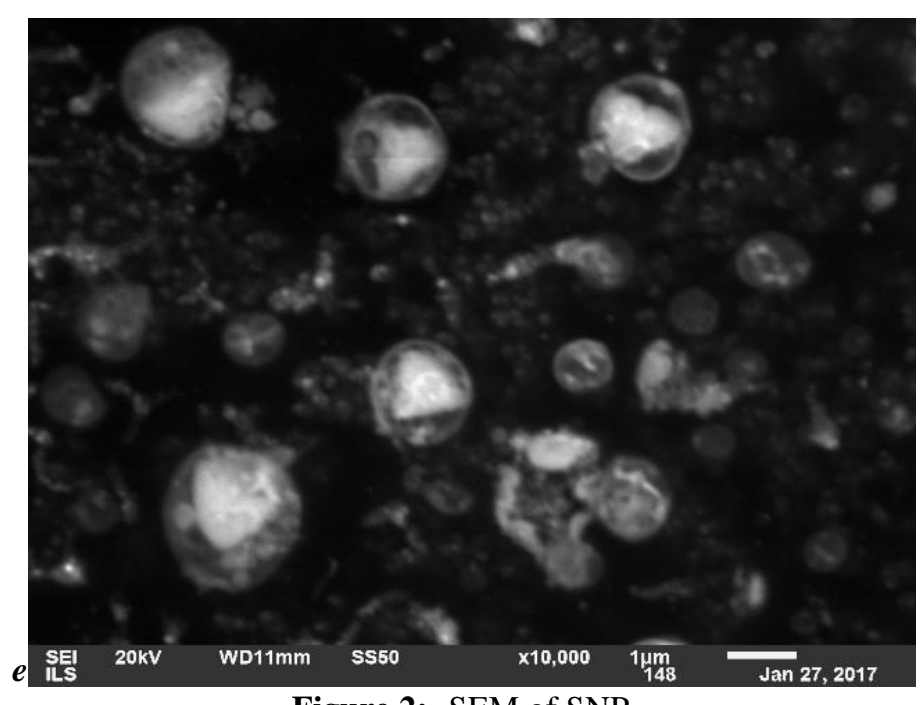

Figure 2:- SEM of SNP

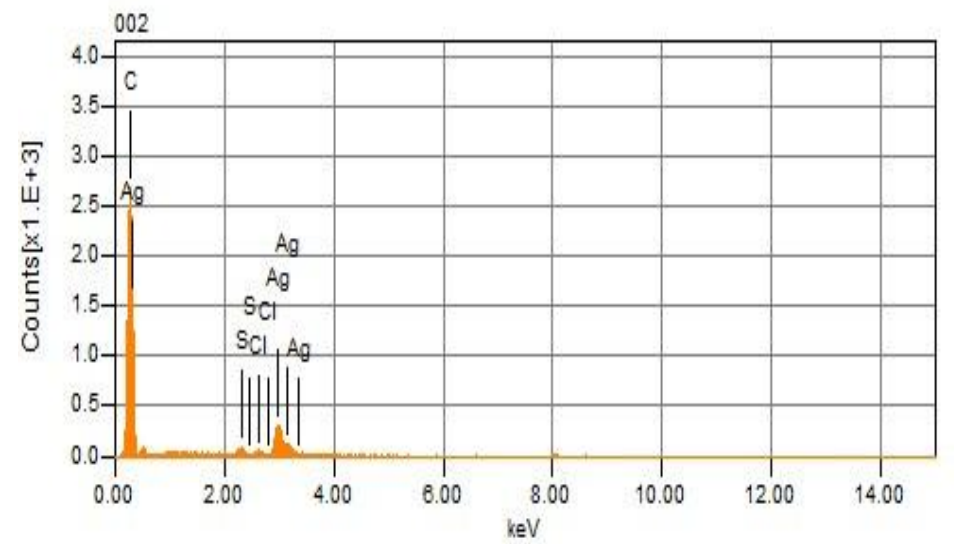

Figure 3:- EDX of SNP 
GUJARAT LABORATORY

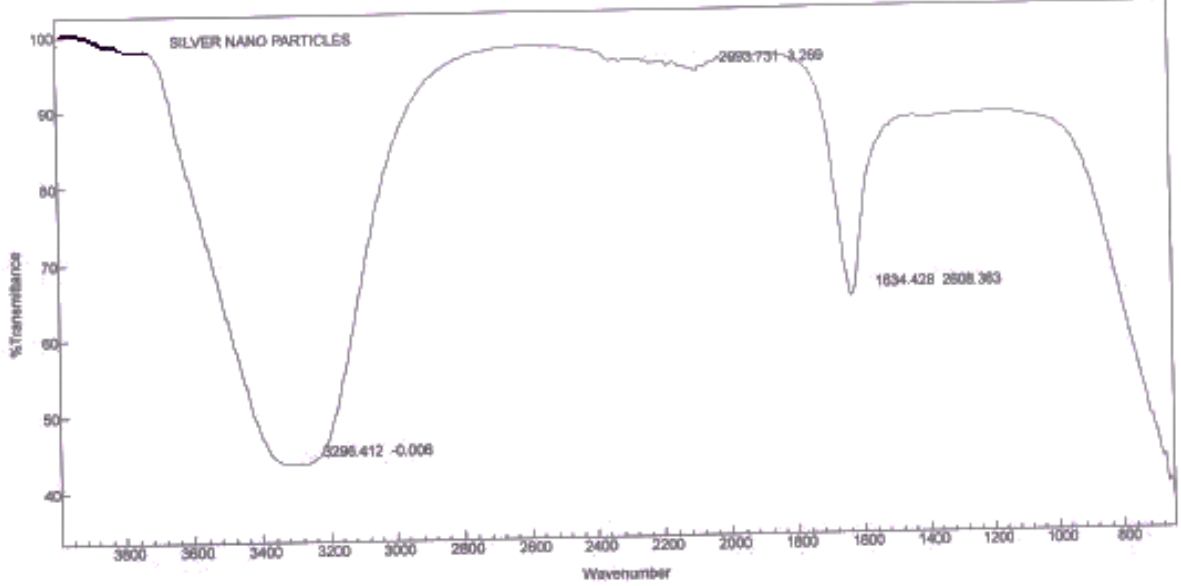

Figure 4:- FTIR of SNP

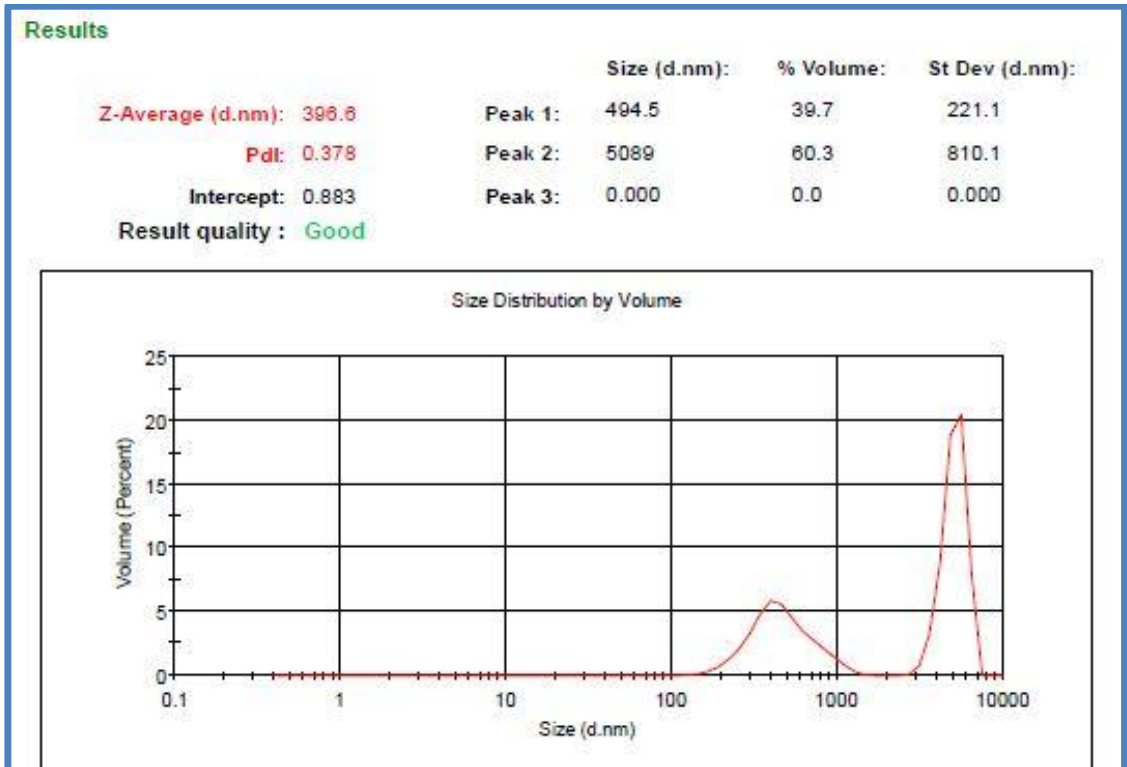

Figure 5:- DLS of SNP 


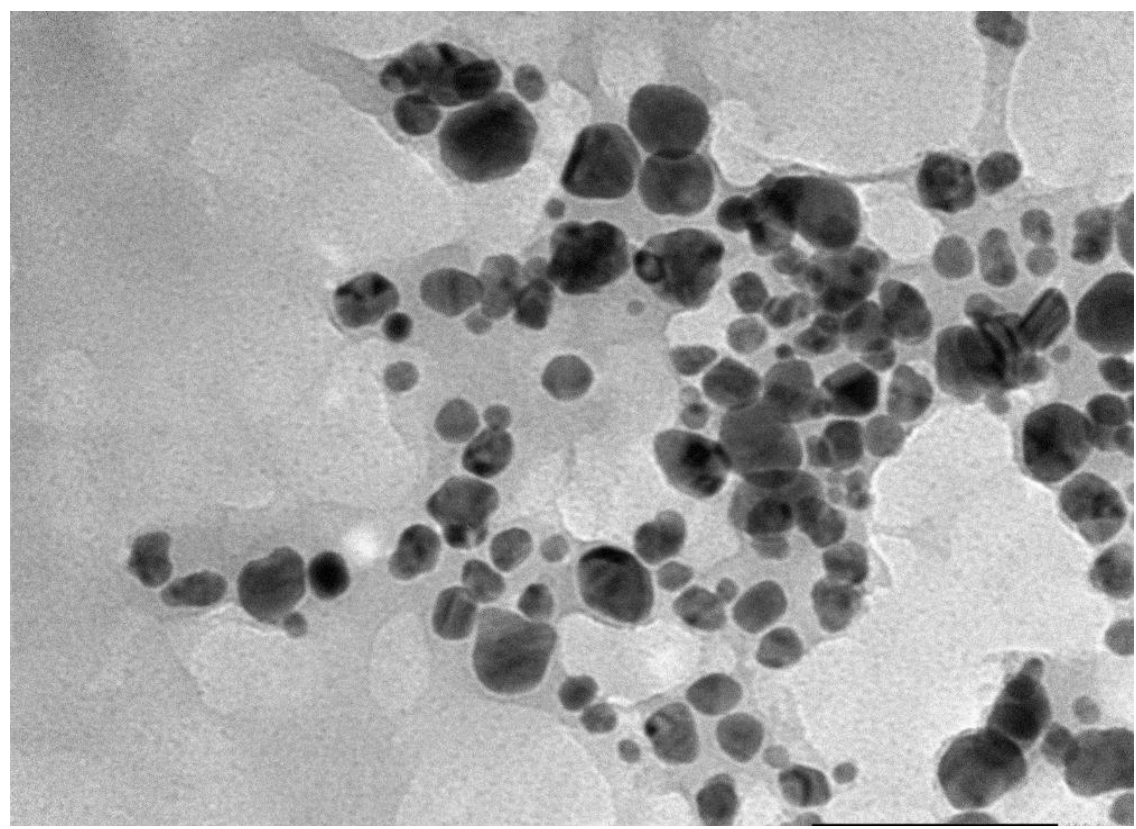

Figure 6:- TEM of SNP

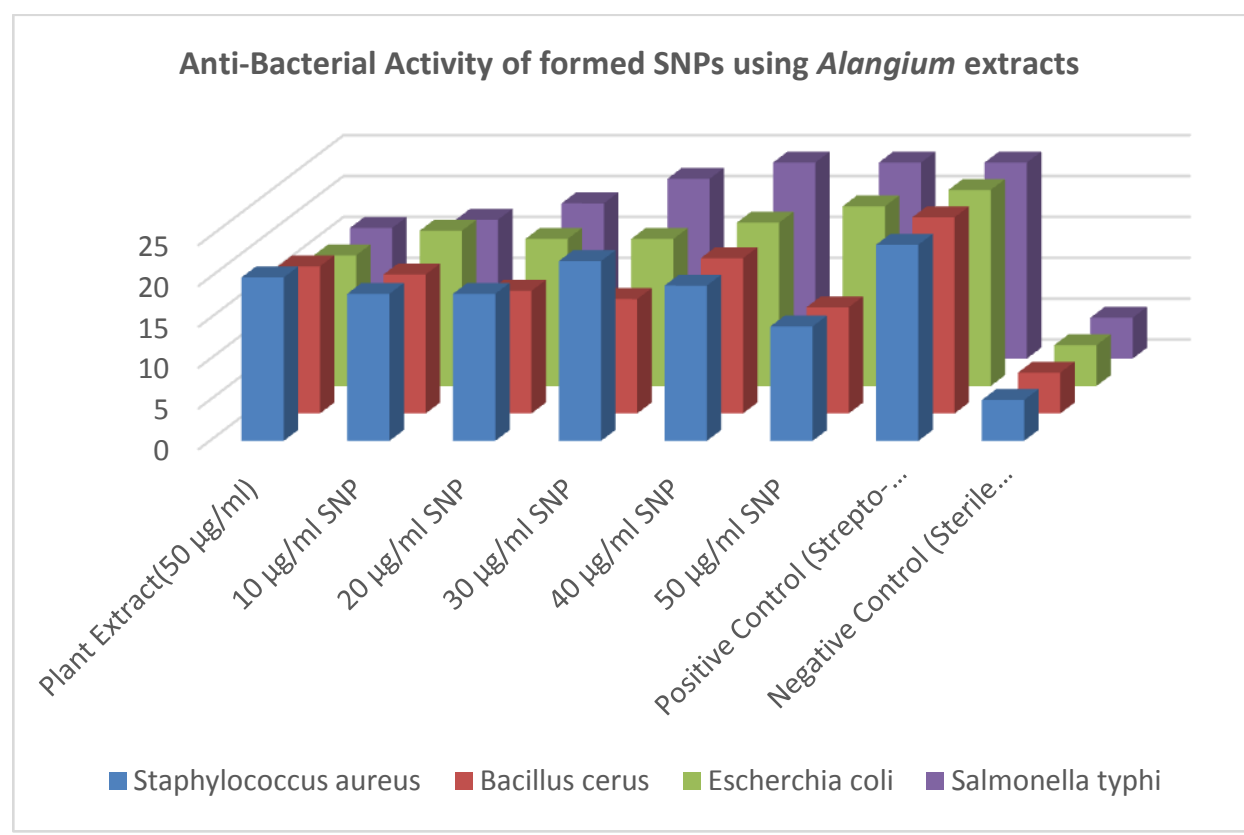

Graph-1:- Anti-Bacterial Activity of formed SNPs using Alangium extracts 


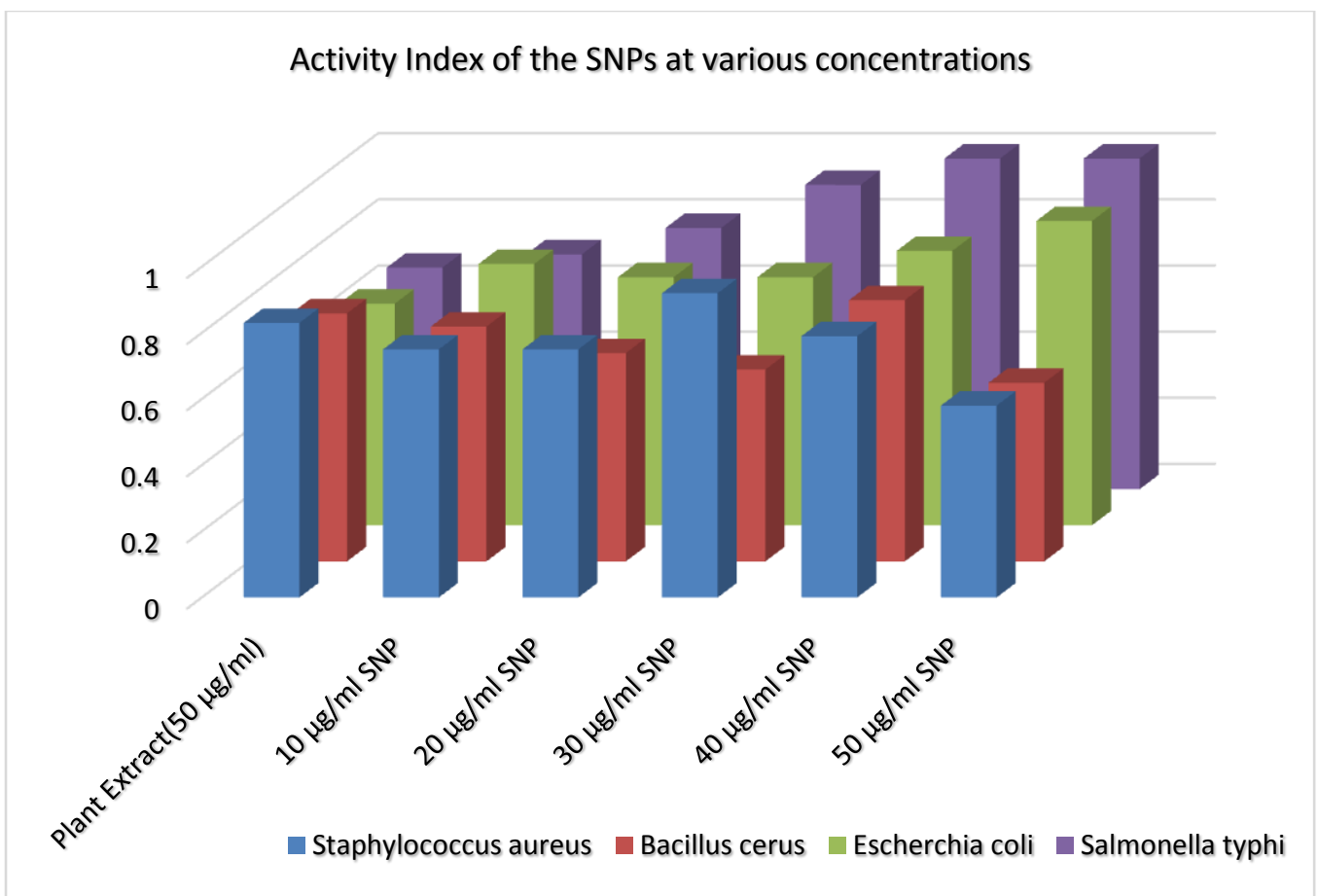

Note: Zone of inhibition by streptomycin as a standard drug $=24 \mathrm{~mm}$ (Mean Value)

$$
\text { Activity Index }(\text { A.I. })=\frac{\text { Mean of Zone of Inbition by SNPs }}{\text { Zone of Inhibition obtained for standard Antibiotic Drug }}
$$

Graph-2:- Activity Index of the SNPs at various concentrations

\section{Conclusions:-}

An innate facile, proficient, and feasible method for the bio-fabrication of silver nanoparticles using aqueous leaf extract of Alangium salvifolium under the normal influence of light and temperature has been used. The biofabrication of silver nanoparticles making use of such a traditionally important medicinal plant without applying any other chemical additives or harsh conditions of temperature etc, thus offers a cost-effective and environmentally benign route for their large-scale commercial production. The SNPs were characterized by UV-visible, SEM-EDX and FT-IR spectrum. Biosynthesis of SNPs using green resources like Alangium salvifolium is a better alternative to chemical synthesis, since this green synthesis is pollutant free and ecofriendly. The biosynthesized AgNPs have shown good antibacterial efficacy and hence has a potential to be used as antibacterial agent against Gram-negative bacteria Salmonella typhii (MTCC: 733) and Escherichia coli (MTCC:425) and Gram positive bacteria Staphylococcus aureus (MTCC:96) and Bacillus cerus (MTCC:430) as well more effectively then the aqueous extracts of Alangium salvifolium. These SNPs were proved to be powerful weapons as antibacterial and antioxidant activity.

\section{Acknowledgement:-}

The authors are thankful to Dr. Edwin A. Pithawala, Asst. Prof. in Microbiology, Khyati Foundation, Ahmedabad, for his valuable inputs and comments.

\section{Bibliography:-}

1. Ángela I. López-Lorente, Boris Mizaikoff,Tr, A.C. (2016): Trends in Analytical Chemistry, Recent advances on the characterization of nanoparticles using infrared spectroscopy, 84(A): 97-106

2. Anil Kumar, S., Abyaneh, M.K., Gosavi, S.W., Kulkarni, S.K., Pasricha, R., Ahmad, A., Khan, M.I. (2007): Nitrate reductase-mediated synthesis of silver nanoparticles from $\mathrm{AgNO}_{3}$. Biotechnol Lett. 29: 439-445.

3. Awwad, A. M, Salem, N.M. and Abdeen,A. O. (2013): "Green synthesis of silver nanoparticles using carob leaf extract and its antibacterial activity," International Journal of Industrial Chemistry, 4, pp. 1-6. 
4. Bali, R., Razak, N., Lumb, A. 2006. "The synthesis of metal nanoparticles inside live plants", In: International Conference on Nanoscience and Nanotechnology, pp.224-227.

5. Balouiri, M.,Sadiki, M., SaadKoraichilbnsouda. (2016) Methods for in vitro evaluating antimicrobial activity: A reviewJournal of Pharmaceutical Analysis 6(2): 71-79

6. Bonet, F., Delmas, V., Grugeon, S. 1999. "Synthesis of Monodisperse Au, Pt, Pd, Ru and Ir Nanoparticles in Ethylene Glycol," Nano Structured Materials, 11(8): 1277-1284,

7. Chandran, S.P., Chaudhary, M., Pasricha, R., Ahmad, A., Sastry,M. (2006): Synthesis of gold nanotriangles and silver nanoparticles using Aloe vera plant extract. Biotechnol Prog. 22: 577-583.

8. Duran, N., Nakazato, G., Seabra, A.B. (2016): Antimicrobial activity of biogenic silver nanoparticles, and silver chloride nanoparticles: an overview and comments Applied Microbiology and Biotechnology, 100 (15): 65556570 .

9. Esumi, K., Tano, T., Torigoe, K. and Meguro, K. (1990): Preparation and Characterization of BiometallicPd-Cu Colloids by Thermal Decomposition of Their Acetate Compounds in Organic Solvents. J. Chem. Mater. 2: 564567.

10. Jain D, Kumar Daima, S., Kachhwaha, S., Kothari S.L. (2009): Synthesis of plant mediated silver nanoparticles using Papaya Fruit Extract and Evaluation of their Antimicrobial Activities. Dig J Nanomater Bios. 4: 557-56.

11. Jain, V.C., Patel, N.M., Shah, D.P., Patel, P.K., Joshi, B.H. (2010): Antioxidant and Antimicrobial Activities of Alangium salvifolium (L.F.Wang) Root. Global Journal of Pharmacology. 4 (1): 13-18.

12. Joseph, S., Mathew, B. (2014): Microwave assisted facile green synthesis of silver and gold nanocatalysts using the leaf extract of Aervalanata. SpectrochimActa A MolBiomolSpectrosc.136PC: 1371-1379.

13. Kora A. J., Arunachala, J. (2012): Green fabrication of silver nanoparticles by gum Tragacanth (Astragalusgummifer): A dual functional reductant andstabilizer. J Nanomater. 2012: 1-8.

14. Mehmood, A., Ghulam, M., Tariq, M.B., Rehana,Kausar.(2013): Phyto-mediated synthesis of silver nanoparticles from Meliaazedarach L. leaf extract: Characterization and antibacterial activity. Arabian Journal of Chemistry. 1-6.

15. Nabikhan, A., Kandasamy, K., Raj,A., Alikunhi, N.M. (2010): Synthesis of antimicrobial silver nanoparticles by callus and leaf extracts from saltmarsh plant, Sesuviumportulacastrum L. Colloids Surf B Biointerfaces. 79: 488-493.

16. Njagi, E.C., Huang, H., Stafford, L., Genuino, H., Galindo, H.M., Collins, J.B., Hoag, G.E. (2011): Biosynthesis of iron and silver nanoparticles at room temperature using aqueous sorghum bran extracts. Langmuir. 27: 264-271.

17. Patel, M.R., Patel, R.A., Varade, D. and Pithawala, K.A.(2017): Green Route Synthesis of Silver Nano Particles using Leaf Extracts of Melaleuca leucadendra, Int. J. of Appl. and Pure Sci. and Agri. 3(3): 48-56

18. Patil, D.C., Patil, V.S., Borase, P.H., Salunke, K.B., Salunkhe, B.R. (2012): Larvicidal activity of silver nanoparticles synthesized using Plumeri arubra plant latex against Aedes aegypti and Anopheles stephensi. Parasitol Res. 110: 1815-1822.

19. Patil, R. S., Kokate,M. R. and Kolekar, S. S. (2012): "Bioinspired synthesis of highly stabilized silver nanoparticles using Ocimum tenuiflorum leaf extract and their antibacterial activity," SpectrochimicaActa Part A, 91, pp. 234-238.

20. Rajeshkumar, S., Malarkodi, C., Paulkumar, K., Vanaja, M., Gnanajobitha, G., Annadurai, G. (2013): Intracellular and extracellular biosynthesis of silver nanoparticles by using marine bacteria Vibrio alginolyticus, Nanoscience and Nanotechnology: An International Journal, 3(1): 21-25.

21. Ratra, M and Gupta,R. (2015): Comprehensive Review on Pharmacological Profile of Alangium salvifolium: A Medicinal Plant, UK Journal of Pharmaceutical and Biosciences. 3(3): 22-28.

22. Roy K, Sarkar C. K., Ghosh, C.K. (2015): Single-step novel biosynthesis of silver nanoparticles using Cucumis sativus fruit extract and study of its phytocatalytic and antibacterial activity. Dig J Nanomater Bios. 10: 107115 .

23. Shahverdi, A.R., Shakibaie, M., Nazari, P. (2011): Basic and practical procedures for microbial synthesis of nanoparticles. In: Rai M, Duran N, editors. Metal nanoparticles in microbiology. Berlin: Springer, 11: 177-97.

24. Shankar, S.S., Rai, A., Ahmad, A., Sastry,M. (2004): Rapid synthesis of Au, Ag, and bimetallic Au core-Ag shell nanoparticles using Neem (Azadirachta indica) leaf broth. J Colloid Interface Sci. 275: 496-502.

25. Sivakumar, P., Nethradevi, C., Renganathan,S. (2012): Synthesis of silver nanoparticles using Lantana camara fruit extract and its effect on pathogens. Asian J Pharm Clin Res., 5: 97-101.

26. Sivaranjani, K. and Meenakshisundaram, M. (2013): "Biological synthesis of silver nanoparticles using Ocium basillicum leaf extract and their antimicrobial activity," International Research Journal of Pharmacy., 4: 225229. 
27. Tan, Y. W., Dai, X. H., Li, Y. F. (2003): "Preparation of Gold, Platinum, Palladium and Silver Nano-particles", Journal of Materials Chemistry, 13(5): 1069-1075.

28. Umer, A., Naveed, S., Ramzan, N. 2012 "Selection of a suitable method for the synthesis of Copper nanoparticles", NANO: Brief Reports and Reviews, World Scientist Publishing Company, 7: 5

29. Vilchis-Nestor, A.R., Sanchez-Mendieta, V., Camacho-Lppez, M.A., Gomez-Espinosa, G.R.M. and ArenasAlatorre, J.A.(2008):Solventless synthesis and optical properties of Au and Ag nanoparticles using Camellia sinensis extract, Mater.Lett.62: 3103-3105.

30. Xavier, A., Kalaiselvi, T.F., Kandhasamy, V., Rajakumari, M., Srinivasan, M.P., Natarajan, K. (2005): Antifungal activity of leaf extracts of Alangiumsalviifolium. J of Tropical Med Plants. 6(2): $179-182$.

31. Zheng, H. and Wang, L. (2013): "Banana Peel Carbon Containing Functional Groups Applied to the Selective Adsorption of Au(III) from WastePrinted Circuit Boards," Soft Nanoscience Letters, vol. 3, pp. 29- 36. 